\title{
A ENFERMAGEM NA PREVENÇÃO DOS CÂNCERES DE MAMA E COLO UTERINO
}

\author{
Helga Yuri DoI ${ }^{1}$ \\ https://orcid.org/0000-0003-3954-8252 \\ Daniela do Carmo Oliveira ${ }^{2}$ \\ https://orcid.org/0000-0002-3901-1298 \\ Cláudio Mendes dos Santos Júnior ${ }^{3}$ \\ https://orcid.org/0000-0002-3486-0741
}

Resumo: Este projeto tem como objetivo oferecer às mulheres informações acerca da prevenção e o diagnóstico precoce dos cânceres que mais as acometem, que são os cânceres de colo de útero e de mama, ofertando educação em saúde na temática proposta e a realização de exames preventivos de CCO e mama em frigoríficos no município de Tangará da Serra, MT. Contou com a parceria da Prefeitura Municipal de Tangará da Serra, MT e acadêmicos do Curso de Enfermagem da Universidade Estadual de Mato Grosso do Campus de Tangará da Serra. Realizaram-se consultas de enfermagem e coleta de CCO nas mulheres que trabalhavam nos frigoríficos de aves e bovinos instalados no município, entre os anos de 2015 a 2017, além da realização de palestras educativas. A inserção da comunidade acadêmica na comunidade local contribui para a aproximação dos acadêmicos às atividades práticas e promove para a sociedade oferta de serviço que muitas vezes possuem dificuldades para acessar nas unidades de saúde.

Palavras-chave: Enfermagem. Saúde da Mulher. Prevenção.

1 Enfermeira, Docente Assistente da Universidade Estadual de Mato Grosso, Coordenadora do Projeto de Extensão Institucionalizado A Enfermagem na Prevenção dos Cânceres de Mama e Colo Uterino, Mestre em Enfermagem pela UFMT na Área de Saúde Sexual e Reprodutiva, Especialista em Enfermagem Obstétrica e Auditoria dos Serviços de Saúde. E-mail: helgaydoi@gmail.com.

2 Enfermeira, Docente Assistente da Universidade Estadual de Mato Grosso Campus de Tangará da Serra, MT, Colaboradora do Projeto de Extensão Institucionalizado A Enfermagem na Prevenção dos Cânceres de Mama e Colo Uterino, Mestre em Enfermagem pela UFMT na Área de Saúde Sexual e Reprodutiva, Especialista em Enfermagem Obstétrica. E-mail: danielacarmoliveira@gmail.com.

3 Enfermeiro da Secretaria Municipal de Saúde de Nortelândia, MT, foi Discente bolsista do Projeto de Extensão Institucionalizado A Enfermagem na Prevenção dos Cânceres de Mama e Colo Uterino. E-mail: claudioogjr@gmail.com. 


\title{
NURSING IN THE PREVENTION OF BREAST AND UTERINE COLUMN CANCERS
}

\begin{abstract}
This project aims to offer women information about the prevention and early diagnosis of the cancers that most affect them, which are cervical and breast cancers, offering health education in the proposed theme and conducting preventive examinations of CCO and breast in refrigerators in the municipality of Tangara da Serra, MT. It counted with the partnership of the Municipality of Tangará da Serra, MT and academic of the Nursing Course of the State University of Mato Grosso do Campus of Tangará da Serra. Nursing and BCC consultations were carried out on women who worked in the poultry and cattle slaughterhouses installed in the municipality between 2015 and 2017, as well as educational lectures. The insertion of the academic community in the local community contributes to the approximation of the academic to the practical activities and promotes to the society the offer of service that often have difficulties to access in the health units.
\end{abstract}

Keywords: Nursing. Women's Health. Prevention.

\section{LA ENFERMERÍA EN LA PREVENCIÓN DE LOS CÁNCERES DE MAMA Y COLO UTERINO}

Resumen: Este proyecto tiene como objetivo ofrecer a las mujeres informaciones acerca de la prevención y el diagnóstico precoz de los cánceres que más las acomete, que son los cánceres de cuello de útero y de mama, ofreciendo educación en salud en la temática propuesta y la realización de exámenes preventivos de CCO y mama en frigoríficos en el municipio de Tangará da Serra, MT. En el presente trabajo se analizaron los resultados obtenidos en el estudio de los resultados de la investigación. Se realizaron consultas de enfermería y recolección de CCO en las mujeres que trabajaban en los frigoríficos de aves y bovinos instalados en el municipio, entre los años de 2015 a 2017, además de la realización de charlas educativas. La inserción de la comunidad académica en la comunidad local contribuye a la aproximación de los académicos a las actividades prácticas y promueve para la sociedad oferta de servicio que muchas veces tienen dificultades para acceder en las unidades de salud.

Palabras Clave: Enfermería. Salud de la Mujer. Prevención.

Submetido em: 03/12/2018

Aceito em: 20/12/2018

A realização desse projeto foi motivada pela coordenadora do mesmo devido a uma ação que executada quando ainda era acadêmica de enfermagem em meados de 2003 no interior de São Paulo. A ação ora mencionada foi muito parecida com o que desenvolvemos nesse projeto de extensão, com a presença de uma enfermeira de UBS, coletaram mais de 100 CCO's em dois dias em um frigorífico de bovinos na cidade de Promissão, SP. Na época, algo inusitado para uma cidade interiorana e idealizada por uma acadêmica. Após anos, a acadêmica se tornou docente de instituição de ensino superior público no 
Estado de Mato Grosso, vindo a ser lotada no Campus de Tangará da Serra MT onde possuía característica semelhante que outrora vivenciou, e a ideia de repetir com seus alunos parecia a oportunidade de motivá-los a adotar parcerias com empresas privadas assim que se tornassem enfermeiros. Caro leitor, essa introdução tem o intuito de contextualizar a importância de projetos de extensão na vida acadêmica dos discentes e docentes, a fim de oferecer a sociedade local uma atenção à saúde que lhes é merecida. Estreitar os caminhos da academia a comunidade local promove o reconhecimento da população acerca da importância da academia, dos acadêmicos e da pesquisa na vida diária de toda a comunidade em que o ensino pode alcançar, a depender de qual área seja. Sendo assim, atualmente o câncer de mama e de colo uterino são os tipos de cânceres femininos que são mais incidentes no Brasil, segundo o INCA (Instituto Nacional de Câncer José de Alencar Gomes da Silva) (2005), porém são os que possuem maior probabilidade de cura quando o diagnóstico da doença é realizado precocemente. É sabido que o Ministério da Saúde (MS) possui programas gratuitos de prevenção e diagnóstico precoce dessas doenças, para as mulheres que utilizam o Sistema Único de Saúde (SUS), porém, os horários de trabalho das mulheres que atuam nos frigoríficos do município de Tangará da Serra, MT, não são horários convencionais ao horário de funcionamento das Unidades de Saúde da Família (USF) onde os exames preventivos estão disponíveis pelo SUS, dificultando ou impossibilitando as mesmas em realizarem os exames periodicamente. Os cânceres de mama e colo uterino, mesmo sendo curáveis quando o diagnostico é precoce, podem trazer sérias complicações, mutilações, constrangimentos e até incapacidade funcional à mulher. $\mathrm{O}$ tratamento oncológico também é um fator desgastante para a vida da mulher e sua família, já que normalmente dura um período mínimo de 06 meses, podendo levar até décadas o tratamento. Além da demora no tratamento, há também os efeitos colaterais que o mesmo provoca como emagrecimento severo, náuseas, vômitos, inapetência, perca momentânea da sociabilidade, alopecia, queimaduras na pele, cirurgias mutilantes, entre outras manifestações clínica que variam de acordo com o tratamento que a mulher receberá pelo seu tipo de tumor. Não menos importante, há também a relação do custo-benefício em relação à prevenção e tratamento do câncer. A prevenção tem um custo efetivo menor que o tratamento, onerando muito menos os cofres públicos, o que nos leva a refletir que mais usuários do SUS poderiam ser atendidos para a prevenção e tratamento de diversas patologias que os assolam. Ficando evidente que 
há a necessidade da academia em se aproximar e promover essas ações de saúde e prevenção no local de trabalho dessas mulheres, em parceria com as instituições de trabalho e em parceria com a Secretaria Municipal de Saúde de Tangará da Serra, MT a fim de minimizar ou sanar alguns problemas ginecológicos mais comuns através da prática dos exames e consultas. Além disso, poder traçar um o perfil das reais necessidades de saúde dessas mulheres em busca de soluções adequadas a seus problemas de saúde, através da coleta de informações de saúde e doença das mesmas. Este projeto objetivou em desenvolver a consulta de enfermagem ginecológica em mulheres que exerçam atividade laboral nos frigoríficos de aves e bovinos, instalados do município de Tangará da Serra, MT, com o intuito de realizar a prevenção dos cânceres de mama e colo uterino e a promoção da saúde para essas mulheres. Além de permitir que o acadêmico do curso de enfermagem possa estabelecer o senso crítico e perceptivo da atuação do enfermeiro dentro da comunidade em que se está inserido, transpondo as barreiras físicas das unidades de saúde e da academia. Historicamente as mulheres têm o seu acesso aos serviços de saúde caracterizados pela desigualdade e exclusão, no âmbito social, racial e de gênero (CORREA; DOI, 2014). Na tentativa de promover uma melhoria para esse cenário, o Ministério da Saúde (MS), vem ao longo de mais de trinta anos (desde a década de 80), lançando programas de atenção à saúde voltada às mulheres em diversas fases da sua vida, seja ela gravídica, puerperal, em situação de violência doméstica e sexual e como não poderia faltar nas doenças que lhe são mais acometidas. Diante disso, em 2013, o Ministério da Saúde lança um exemplar dos Cadernos de Atenção Básica sobre o Controle dos Cânceres do Colo do Útero e da Mama com o intuito de promover maior acesso à temática para os profissionais que atuam no Sistema Único de Saúde (SUS) a fim de que haja uma melhor assistência à saúde a essas mulheres (BRASIL, 2013). Diante desse contexto, a Atenção Primária à Saúde (APS) é a principal porta de entrada da comunidade aos serviços de saúde pública, pois é através de ações que utilizam de pouca tecnologia e baixo custo aos serviços públicos que é possível prevenir ou sanar doenças e/ou complicações mais comuns entre a população (STARFIELD, 2002). E o enfermeiro, como profissional essencial da APS, possui autonomia e capacitação para realização da consulta de enfermagem ginecológica e coleta de material histológico do colo uterino. Sendo que uma das atividades a serem realizadas pela APS é a prevenção das doenças e/ou a complicação das mesmas. Porém, quando nos deparamos com mulheres que possuem atividade 
laboral fora do domicílio, e que muitas vezes dependem desse trabalho para sustentar toda a família, percebe-se que a prioridade é o trabalho e não o cuidado à sua própria saúde. Mesmo que haja unidades de saúde próximas ao seu domicílio, a busca pelo autocuidado não é efetiva, pois muitas vezes, o horário da folga do seu trabalho não é compatível com o horário de atendimento dos serviços de saúde. E mesmo que seja um direito dessas mulheres a busca pelo autocuidado nas unidades, em seu horário de trabalho, apresentando atestado médico ou declaração de comparecimento, as empresas em que laboram não apoiam essa postura por parte das trabalhadoras. O que pode causar nessas, $o$ receio da demissão e perca da fonte de sustento da sua família, o que propicia a essas mulheres a busca pela automedicação ou então o uso de medidas caseiras baseadas em crendices populares, a fim de sanar os sinais e sintomas de uma doença ginecológica que a mesma possui. O que pode gerar prejuízos irreversíveis, pois há o risco de mascarar uma doença grave e que necessite de tratamento efetivo, atrasando assim a busca pela cura da doença. Diante dessa perspectiva, promover a difusão de informações sobre promoção à saúde, a respeito de estabelecimentos de saúde e sobre a prevenção de agravos, oferecendo conhecimentos mais amplos sobre questões relativas à saúde, possibilita que a mulher tenha melhores condições para a tomada de decisão acerca da sua própria condição de saúde (ESCOREL; MOREIRA, 2008; MACHADO; VIEIRA; SILVA, 2010). Os cânceres de colo uterino e mama podem ser prevenidos e diagnosticados de maneira simples, rápida e com um custo efetivamente baixo quando comparados aos tratamentos que as mulheres acometidas por uma dessas doenças estão sujeitas. Quando tratamos acerca do assunto câncer de mama, logo nos vem à mente a mulher mutilada, em que é retirada parte ou totalidade da sua mama, órgão esse que está relacionado aos prazeres sexuais e à alimentação do próprio filho. Porém, a fim de evitar essa agressão à vida social e sexual da mulher, o diagnóstico precoce e o tratamento efetivo podem ser as formas de evitar que esses traumas atinjam mais mulheres em todo o país (INCA, 2014). Através do autoexame das mamas, que deve ser realizado mensalmente pelas próprias mulheres, é possível através da palpação, detectar tumores superficiais a partir de $01(\mathrm{um}) \mathrm{cm}$, ou seja, em um estágio que ainda é possível tratamento e maiores chances de cura (INCA, 2014). Segundo o INCA, no Brasil, há estimativas que apontam que só em 2018, quase sessenta mil mulheres desenvolverão o câncer de mama e o de colo uterino mais de dezesseis mil mulheres (INCA, 2018). Já o câncer de colo uterino está associado à 
infecção pelo vírus HPV (Papilomavírus Humano), há estimativa de que 80\% das mulheres com vida sexual ativa irá adquirir a infecção pelo HPV ao longo de suas vidas (SANJOSE, 2007). Quando essa infecção não é diagnosticada e nem tratada, há o risco de desenvolver uma infecção persistente, podendo levar a diferenciação celular provocando lesão intraepitelial escamosa de alto grau e adenocarcinoma in situ (WHO, 2008). O esfregaço de Papanicolaou é o método mais utilizado para detectar a presença de células atípicas no óstio cervical, sendo que o material coletado é encaminhado ao laboratório de histopatologia e após a análise, possibilita o tratamento precoce. Este exame é bastante simples, causa apenas um pequeno desconforto na mulher, e um dos profissionais que preferencialmente vem realizando esse procedimento na APS é o enfermeiro. Portanto, a realização dessas ações no ambiente de trabalho da mulher, pode contribuir efetivamente com a melhoria das condições de saúde da mesma e promover o estreitamento da comunidade acadêmica com a comunidade externa do município, permitindo a efetivação prática da disseminação do saberes desenvolvidos na academia e permitindo a contribuição direta para a comunidade externa. Além disso, a comunidade acadêmica poderá entender, através dos dados e informações coletadas durante o projeto de extensão, quais são as reais limitações que essa comunidade específica apresenta, podendo caracterizá-la com o intuito de buscar soluções mais efetivas para a busca do autocuidado dessas mulheres, além da prevenção e o tratamento efetivo para as enfermidades ginecológicas que as acometem. Durante o período desse projeto, foram realizadas duzentos e vinte e seis consultas de enfermagem ginecológica, avaliando as mamas e coletando material histocitopatológico do colo uterino, além de palestras educativas e instrutivas para mais de quatrocentas mulheres de todos os setores dos frigoríficos, acerca das doenças femininas e sexualmente transmissíveis. Posteriormente encaminhamos o material coletado para a análise laboratorial, sendo selecionados os resultados que havia a necessidade de tratamento e/ou acompanhamento médico. Para as mulheres que presenciamos leucorréias durante o exame especular, foram receitadas pomadas ginecológicas conforme o programa ministerial da saúde da mulher e de abordagem sindrômica em DST's, de acordo com as características que apresentavam. Além de informações para evitar a recorrências destas, a transmissão para os parceiros sexuais e medidas de proteção e higiene a fim de evita-las As participantes eram residentes do município de Tangará da Serra, MT, porém com uma grande variação de naturalidade, pois havia muitas mulheres 
provenientes da região norte e nordeste que buscaram o município especificamente para o trabalho. Essas mulheres vieram em busca de melhores oportunidades de trabalho e consequentemente da melhoria da qualidade de vida que em suas regiões de origem são precárias. A faixa etária das mesmas variou entre 17 a 48 anos de idade, ou seja, mulheres relativamente jovens em plena capacidade laboral, sexual e de vida. Em relação à renda financeira dessas colaboradoras variaram entre um salário mínimo a até cinco salários mínimos, sendo que prevalece na maioria dos casos até dois salários mínimos. Porém muitas dessas mulheres eram as únicas que proviam renda em casa. Infelizmente, tivemos algumas dificuldades para desenvolver o projeto, pois após o segundo semestre da realização do mesmo, houve mudança dos proprietários de um dos frigoríficos (que era o que tínhamos mais apoio da gestão), o que provocou dificuldades na realização dos procedimentos, pois a atual gestão não liberava maior quantitativo de mulheres para participar. $\mathrm{O}$ que motivou uma redução considerável na participação dessas no agendamento para as consultas e procedimentos realizados, pois as mesmas nos informava que os encarregados dos setores estavam reclamando da demora das mesmas para retornarem a produção. Outra dificuldade encontrada foi na parceria com o município na liberação de materiais para coleta de CCO (que em uma das ocasiões estava em falta no município, ou seja, não havia materiais como lâmina para microscopia fosca, escova cervical e até espéculos vaginais) e na análise do material coletado, pois o município ficou um período sem nenhum laboratório de análise conveniada que prestasse o serviço de análise dos materiais coletados para a rede municipal. Isso ocasionou em uma diminuição do número de mulheres para a coleta de material histopatológico do colo uterino, pois a análise do material coletado teve que ser custeado pela professora coordenadora desse projeto. Como não havia nenhum financiamento externo que pudesse custear esses materiais e da análise histopatológica, a quantidade custeada ficou no limite do orçamento pessoal da pesquisadora. Tais dificuldades não impediram a realização das ações, mas reduziram sua capacidade de atingir maior número de mulheres que gostariam de ter acesso à consulta e a coleta do exame e que a equipe de extensionista estava apta a atender. Porém nos demonstrou a necessidade das mesmas em realizar o cuidado à saúde, pois trabalhadoras com restrições laborais tão impetuosas e dificuldades do próprio município em prover de materiais e laboratórios conveniados que prestem o serviço, reduz significativamente as oportunidades para elas realizarem esses procedimentos. Todas as 
mulheres possuíam vida sexual ativa e a maioria delas apresentava alguma queixa relacionada à dispareunia ou leucorréias, que tratavam com medidas caseiras para alívio dos sintomas. Fato esse pôde ser comprovado durante as consultas de enfermagem, pois algumas apresentavam desconforto acima do esperado na introdução dos espéculos ou então a presença das leucorréias visíveis. Vale ressaltar que o trabalho no setor de produção dos frigoríficos ocorre em locais excessivamente quentes ou frios, o que propicia a proliferação de microrganismos patógenos na região da vulva e vagina. Ou seja, nos setores excessivamente frios (câmara fria), houve mulheres que faziam uso de até três calças para suportar a temperatura do local de trabalho, impedindo que haja circulação de ar na região íntima, promovendo o abafamento do local. Já algumas trabalhavam em locais excessivamente quentes sem ao menos possuir uma roupa que aliviasse ou protegesse ou então equipamentos que melhorassem a temperatura do ambiente. Não havia também nenhum limite máximo para a permanência delas no local de trabalho com temperaturas extremas, ou seja, o tempo que permaneciam no local era o mesmo de qualquer trabalhador regido pela Consolidação das Leis de Trabalho no Brasil. Como o ganho salarial corresponde ao quantitativo de produção que elaboram, elas cumprem carga horária de oito horas trabalhadas. Além disso, a maioria delas fazia uso de calcinhas de material sintético o que piora também a circulação de ar na região íntima, mas tivemos a oportunidade de orientá-las a fazer uso de calcinha de algodão e a higienização com maior frequência da vulva, mesmo durante o trabalho, assim poderia reduzir os desconfortos e a proliferação das leucorréias patogênicas. Mas muitas ainda relatavam que não podiam demorar muito tempo fora da produção para usar o banheiro e não podiam sair muitas vezes, todos esses fatores são limitantes no autocuidado das mesmas durante o ambiente de trabalho. Mesmo não havendo apoio incondicional da administração dos frigoríficos, os mesmos ainda abriam as portas para que as ações ocorressem, pois de certa forma, os mesmos necessitam cumprir com obrigações legais relacionados à segurança do trabalhador. E ações como prevenção de doenças é uma das exigências que precisam ser cumpridas pelo empregador. Infelizmente podemos notar que se não há uma obrigatoriedade por parte da empresa em oferecer às suas trabalhadoras informações ou condições que propiciem a busca pelo autocuidado, a empresa não proporcionaria tal ação, o que nos faz refletir não apenas sobre a exclusão do gênero, mas também ao massacre da trabalhadora a condições pouco humanas de trabalho, aonde o poder de 
produção máximo por ela deve ocorrer mesmo custando o prejuízo da própria saúde. Outro fator a ser pontuado se dá que a maioria dessas mulheres era natural de estados das regiões norte e nordeste, estando nessa região em busca de trabalho e sustento da família que vieram com elas ou que continuavam no estado de origem. Essas regiões são caracterizadas pela escassez de recursos financeiros provocando um abismo social, cultural e étnico principalmente quando relacionados à busca pelo autocuidado. Portanto, foi possível através dessa atividade extensionista, promover a contribuição para reformulações de concepções e práticas curriculares da Universidade, bem como para sistematização/divulgação do conhecimento produzido, cumprindo com o preceito da indissociabilidade entre extensão, ensino e pesquisa, com intuito de integrar as ações para atender as demandas da sociedade, buscando o comprometimento da comunidade universitária com seus interesses e necessidades sociais. Implementando um processo de socialização do conhecimento acadêmico de modo que os resultados oriundos das ações puderam contribuir na formação técnico-científica, cultural, social e pessoal dos acadêmicos. Essa relação transformadora entre a Universidade e a sociedade, proporciona a contribuição à inclusão de grupos sociais, ampliando oportunidades educacionais e de acesso aos processos de formação e de qualificação promovidos pela Universidade. Além de promover uma ampliação do acesso a ações de saúde da comunidade local, os acadêmicos puderam refletir também acerca das condições sociais de trabalho que essas mulheres enfrentam no seu dia a dia. Que além do compromisso com o trabalho formal há ainda o desempenho dessas mulheres como esposas, mães e donas do lar. Perceber de uma forma holística a vida da mulher brasileira que trabalha fora de casa, sejam nos âmbitos sociais, sexuais, espirituais, financeiros, étnicos, entre outros, nos faz compreender de que forma a política social do nosso país anda na contramão das reais necessidades de saúde, sendo então pouco efetivas, apesar de todos os programas ministeriais existentes. Se não houver engajamento efetivo do poder público atrelado às empresas privadas, infelizmente muitas mulheres ainda sofrerão com doenças que são preveníveis e que possuem chances de curas como os cânceres femininos. Devemos buscar o empoderamento feminino pelo cuidado ao próprio corpo com conhecimento pautado na ciência a fim de que a mesma possa decidir com consciência e propriedade intelectual o que é melhor para ela e seu corpo. Muito se discute sobre a mulher ter o poder de escolha acerca de procedimentos ou atitudes que estejam relacionados ao próprio corpo ou a própria sexualidade, quando ainda 
não oferecemos, de forma maciça, conhecimento para que primeiramente ela saiba promover seu autocuidado baseado em informações fidedignas. Buscar entender todo esse contexto e envolver a comunidade acadêmica nesse processo de melhoria da qualidade de vida e saúde da comunidade local permite a formação de profissionais com foco na inovação do trabalho para o bem coletivo. Formamos não apenas o profissional tecnicamente capacitado, mas também, um cidadão para um futuro melhor para nossa nação.

\section{REFERÊNCIAS}

BRASIL. Ministério da Saúde. Secretaria de Atenção à Saúde. Departamento de Atenção Básica. Controle dos cânceres do colo do útero e da mama. 2. ed. Brasília: Ministério da Saúde, 2013.

CORREA, Aurea Cristina de Paula; DOI, Helga Yuri. Contrarreferência de mulheres que vivenciaram gestação de risco a Unidades de Saúde da Família em Cuiabá. Cienc Cuid Saude. Jan/Mar; v.13, n.1, p. 104-110, 2014.

ESCOREL, Sarah; MOREIRA, Marcelo Rasga. Participação social. In: GIOVANELLA, Ligia; ESCOREL, Sarah; LOBATO, Lenaura de Vasconcelos Costa. (Orgs.). Políticas e sistemas de saúde no Brasil. Rio de Janeiro: FIOCRUZ, 2008.

INCA. Instituto Nacional de Câncer (Brasil). Portaria 2439. Política Nacional de Atenção Oncológica. 2005.

Instituto Nacional de Câncer (Brasil). A mulher e o câncer de mama no Brasil. Coordenação Geral de Prevenção e Vigilância, Divisão de Detecção Precoce e Apoio à Organização de Rede - Rio de Janeiro: INCA, 2014. . Instituto Nacional de Câncer (Brasil). Estimativa de Câncer no Brasil. 2018.

MACHADO, Maria de Fátima Antero Sousa; VIEIRA, Neiva Francenely Cunha; SILVA, Raimunda Magalhães da. Compreensão das mudanças comportamentais do usuário no Programa Saúde da Família por meio da participação habilitadora. Revista Ciência e Saúde Coletiva. Rio de Janeiro, v.15, n.4, p.2133-2143, 2010.

SANJOSÉ Silvia de et al. Worldwide prevalence and genotype distribution of cervical human papillomavirus DNA in women with normal cytology: a meta-analysis. The Lancet infectious diseases, New York, v.7 n.7, p.453-459, jul. 2007.

STARFIELD, Barbara. Atenção primária: equilíbrio entre necessidades de saúde, serviços e tecnologia. 2. ed. UNESCO: Ministério da Saúde, 2002.

WORLD HEALTH ORGANIZATION. International Agency for Research on Cancer. World Cancer Report 2008. Lyon: 2008. 